\title{
ESTIMATION OF THERMOPHYSICAL PROPERTIES OF VEGETABLE OILS FOR CREATION DATABASE TO ENGINEERING CALCULATIONS
}

\author{
Gisele Cristina Rabelo Silva ${ }^{1}$ and Maria Helena Caño de Andrade ${ }^{2}$
}

\author{
${ }^{1}$ Federal University of São João del-Rei - UFSJ, Divinópolis - Minas Gerais, Brazil. \\ ${ }^{2}$ Federal University of Minas Gerais - UFMG, Belo Horizonte - Minas Gerais, Brazil.
}

Email: giselec@ufsj.edu.br, cano@ufmg.br

Received: Apr 14 ${ }^{\text {th }}, 2020$

Accepted: Jun $24^{\text {th }}, 2020$

Published: June $30^{\text {th }}, 2020$

Copyright (C2016 by authors and Galileo Institute of Technology and Education of the Amazon (ITEGAM).

This work is licensed under the Creative Commons Attribution International License (CC BY 4.0).

https://creativecommons.org/licen ses/by/4.0/

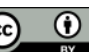

Opea Acten:

\begin{abstract}
Researches focusing on the development of biofuel production processes have increased significantly in recent years, mainly for environmental and economic issues. The identification of low-cost raw materials and the development of simulation models able to predict the conditions of production and the properties of the components may be the way to optimize these processes. Biodiesel is an alternative renewable fuel to petroleum-based diesel departing from vegetal oils (fresh or reused) as well as some kinds of animal tallows. The knowledge of thermophysical properties of the components of the feed is crucial for optimization this process. The experimental determination of these properties is complex and high costs, as can occur chemical degradation during analysis or it is impossible to have them this like pure components. Thus, the objective of this study was to evaluate methods for predicting physical and thermodynamic properties, in order to develop a database of the compounds involved in the biofuels production's process and to recommend appropriate methods based on accuracy and consistency of data obtained. In view of that, this work investigated the performance of groups contribution methods and fragment-based approach in the calculation of as normal boiling temperature, critical temperature, critical pressure, critical volume, acentric factor, heat capacity, vapor pressure, enthalpy of vaporization liquid density and enthalpy of formation. At the end of this work, the most viable models were recommended for each property evaluated, comparing the estimated values to the experimental data available in the literature. Finally, a database with physical and chemical properties of vegetable oils was created to use in engineering calculations.
\end{abstract}

Keywords: Vegetable oils, Biodiesel, Thermophysical properties.

\section{INTRODUCTION}

The decline in available oil reserves and stricter environmental regulations has motivated global interest in studies for the discovery and improvement of renewable energy sources, especially biofuels.

Vegetable oils and fats animal's types used in the manufacture of biofuel, can cause changes in their properties. In other words, biodiesel can present different properties by the chemical composition of raw materials, for example, a low performance in relation to the properties of cold flow [1].
The literature reveals that there is a large volume of researches conducted in the design of processes and manufacture of biofuels from vegetable oils, but the experimental data available for thermodynamic properties of vegetable oils and/or predict methods are limited [2-6].

The scarcity of data on the thermophysical properties of biodiesel components and vegetable oils can be related to the difficulty in obtaining them in pure form and in the performance of experiments, as these substances can degrade under severe conditions [7], [8]. However, vegetable oils aren't composed only by a triacylglycerol. Oils and fats can contain dozens of different triacylglycerols (TAG), as tripalmitin, tristearin and triolein. 
Diacylglycerols (DAG), monoacylglycerols (MAG) and free fatty acids (FA) are also components of vegetable oils and have few properties reported in the databases, as well as methyl and ethyl esters [4], [9-12].

Group Contribution (CG) methods have been used in recent years to estimate some physicochemical properties of organic substances, such as normal boiling point, critical properties and acentric factors [3], [11], [13]. The GC considers that the properties of molecules depend on the nature of atoms and the types of chemical bonds within molecules [14]. In addition to GC, methods with the principle of contributor fragments have been used for calculations that consider that the properties of molecules are established from the contributions of their functional groups [8]. These methodologies need only small amounts of information about the substances in order to obtain a reliable estimate. Although there are many methods in the literature, each of them has built-in premises and practical limits that must be applied. Therefore, selecting the most appropriate models for predicting thermophysical properties is extremely important for achieving realistic results in a process simulation.

\section{METHODOLOGY}

\section{II.1 MODELING OF PREDICTING THERMOPHYSICAL PROPERTIES}

For the development of property estimates, electronic spreadsheets were created in MS-Excel ${ }^{\circledR}$ with equation sequences for the calculations of the methods.

For the application of the methods of estimating properties, the molecules of the compounds of interest (TAGs, DAGs, MAGs and FA) were drawn and, then, the functional groups identified and quantified.

Example: A molecule of triacylglycerol PLO, formed by the junction of palmitic fatty acids $(\mathrm{P})$, linoleic $(\mathrm{L})$ and oleic $(\mathrm{O})$ in a glycerol molecule. Its chemical formula is represented by $\mathrm{C}_{55} \mathrm{H}_{100} \mathrm{O}_{6}$. Figure 1 represents the triacylglycerol PLO molecule.

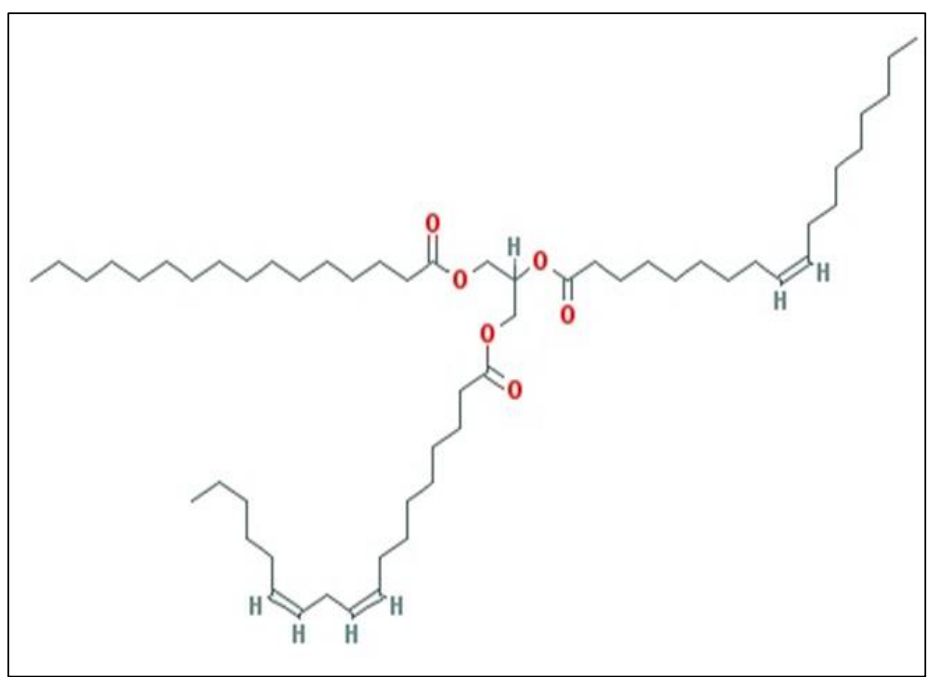

Figure 1: Chemical structure of triacylglycerol PLO. Source: Authors, (2020).

The groups present in the molecular structure represent in Figure 1 were counted for the methods of contribution of groups showed in Table 1, JOBACK [15] and GANI [16].
Table 1: Occurrence of the groups for the JOBACK and GANI method for the PLO triacylglycerol.

\begin{tabular}{|c|c|c|c|}
\hline $\begin{array}{c}\text { JOBACK } \\
\text { groups }\end{array}$ & Score & $\begin{array}{c}\text { GANI } \\
\text { groups }\end{array}$ & Score \\
\hline $\mathbf{C H}_{3}$ & 3 & $\mathbf{C H}_{3}$ & 3 \\
\hline$>\mathbf{C H}_{2}$ & 42 & $>\mathbf{C H}_{2}$ & 40 \\
\hline$>\mathbf{C H}-$ & 4 & $>\mathbf{C H}-$ & 1 \\
\hline $\mathbf{- C O O}-$ & 3 & $-\mathbf{C H}$ - $\mathbf{C O O}-(\mathbf{C})$ & 2 \\
\hline =CH- & 3 & $-\mathbf{C O O}-$ & 1 \\
\hline & & $-\mathbf{C H}=\mathbf{C H}-$ & 3 \\
\hline
\end{tabular}

Source: Authors, (2020).

Each of these groups has a contribution value depending on the property to be calculated and method used. Thus, it's possible to use the equations of the methods safely to predict the properties.

Equations necessary for the calculations of GC methods and fragments approach are described below.

Normal boiling temperature $\left(T_{b}\right)$ : $T_{b}$ is the temperature at which the vapor pressure equals the external or atmospheric pressure.

Developed an advanced method of group contribution based on the groups of the thermodynamic model Universal Functional Activity Coefficient (UNIFAC) [16-17]. In addition, the authors added the so-called "second order" contributions that allow differentiating molecules from isomers, molecules that have the same groups, located together or not, resonance structures, among others [8].

The equations of the JOBACK and GANI models for $\mathrm{Tb}$ estimation are represented by equations 1 and 2 .

JOBACK:

$$
T_{b}=198+\sum_{k} N_{k}\left(T_{b k}\right)
$$

GANI:

$$
T_{b}=204.359 \times \ln \left(\sum_{k} N_{k} T_{b k}\right)
$$

where $N_{k}$ represents the number of groups of type $k$ and $T_{b k}$ the contribution to the normal boiling temperature of groups $\mathrm{k}$.

The semi-empirical approach of [18], [19] was also used to calculate of boiling temperature of TAGs, DAGs and MAGs is implemented the basis of fragments of the constituents. A relationship between the boiling temperature of each of the fragments of the TAGs (fatty acids and glycerol) and pressure was applied. Therefore, the experimental data of [20], [21] on the temperature of each of the fragments were adjusted to Equation 3.

ZONG:

$$
T_{b}^{a}=a \times \ln (P)+b
$$

where $\mathrm{a}$ and $\mathrm{b}$ are the adjustment parameters of each fragment, $\mathrm{T}_{\mathrm{b}}{ }^{\mathrm{a}}$ is the boiling temperature of fragment a $(\mathrm{K})$ and $\mathrm{P}$ is the vapor pressure $(\mathrm{mmHg})$. Knowing the value of $\mathrm{T}_{\mathrm{b}}{ }^{\mathrm{a}}$ for each of the fragments, it was possible to calculate the value of $T_{b}{ }^{\text {TAG }}$ using Equation 4:

$$
T_{b}^{T A G}=\frac{\sum N_{F r a g, a} \times T_{b}^{a}}{3}
$$


$\mathrm{T}_{\mathrm{b}}{ }^{\mathrm{TAG}}$ represents normal boiling temperature of triacylglycerol (K) and $\mathrm{N}_{\text {Frag }}$ number of fragments of a.

Critical properties $\left(\mathrm{P}_{\mathrm{c}}, \mathrm{V}_{\mathrm{c}}, \mathrm{T}_{\mathrm{c}}\right.$ and $\left.\mathrm{Z}_{\mathrm{c}}\right)$ : Pressure $\left(\mathrm{P}_{\mathrm{c}}\right)$, volume $\left(\mathrm{V}_{\mathrm{c}}\right)$, temperature $\left(\mathrm{T}_{\mathrm{c}}\right)$ and compressibility factor $\left(\mathrm{Z}_{\mathrm{c}}\right)$ critical are parameters used in many volumetric, thermodynamic and transport correlations based on the theory of corresponding states to estimate gas and liquid properties.

According to [8], the experimental determination of these properties is difficult, as chemical degradation can occur at high temperatures, especially for long chain components.

The critical point of glycerol was defined by [22] through an unconventional methodology called pulse-heating, being the only experimental measure available in the literature. The critical temperature obtained was $850 \mathrm{~K}$ and the critical pressure was 75 bar. As glycerol begins to undergo thermal degradation from 510 K (DIPPR, 2019), the critical parameters of this molecule can be included in predictive calculations.

The estimation methods evaluated in this study were: [15], [16], [23], [24]. The first method requires only information on the structure of the compound, while the other methods require values of molar mass and boiling temperature. The methods are represented by Equation 5 to Equation 16.

JOBACK:

$$
\begin{gathered}
T_{c}=T_{b}\left[0.584+0.965 \sum_{k} N_{k}\left(T_{c k}\right)-\left(\sum_{k} N_{k}\left(T_{c k}\right)\right)^{2}\right]^{-1}(5) \\
P_{c}=\left[0.113+0.0032 N_{a t}-\sum_{k} N_{k}\left(P_{c k}\right)\right]^{-2} \\
V_{c}=17.5+\sum_{k} N_{k}\left(V_{c k}\right)
\end{gathered}
$$

GANI:

$$
\begin{gathered}
T_{c}=181.28 \times \ln \left(\sum_{k} N_{k} T_{c k}\right) \\
P_{c}=\left[\sum_{k} N_{k} P_{c k}+0.10022\right]^{-2}+1.3705 \\
V_{c}=\left(\sum_{k} N_{k}\left(V_{c k}\right)-0.00435\right) \times 1000.0
\end{gathered}
$$

AMBROSE:

$$
\begin{gathered}
T_{c}=T_{b}\left[1+\left(1.242+\sum_{k} N_{k}\left(T_{c k}\right)\right)^{-1}\right] \\
P_{c}=M_{M}\left[0.339+\sum_{k} N_{k}\left(T_{c k}\right)\right]^{-2}
\end{gathered}
$$

$$
V_{c}=40+\sum_{k} N_{k}\left(V_{c k}\right)
$$

LYDERSEN:

$$
\begin{gathered}
T_{c}=\frac{T_{b}}{0.567+\sum N_{k}\left(T_{c k}\right)-\left(\sum N_{k}\left(T_{c k}\right)\right)^{2}} \\
P_{c}=\frac{M_{M}}{\left(0.34+\sum N_{k}\left(P_{c k}\right)\right)^{2}} \\
V_{c}=40+\sum N_{k}\left(V_{c k}\right)
\end{gathered}
$$

$\mathrm{T}_{\mathrm{ck}}, \mathrm{P}_{\mathrm{ck}}$ and $\mathrm{V}_{\mathrm{ck}}$ represent the contributions of each functional group and that vary numerically depending on the method of contribution of groups. $\mathrm{N}_{\mathrm{at}}$ is the number of atoms in the molecule, in the critical pressure equation for the JOBACK method. $\mathrm{M}_{\mathrm{M}}$ the molar mass, $\mathrm{N}_{\mathrm{k}}$ is the number of times the group " $k$ " appears in the molecule. $T_{c}$ is given in Kelvin, $P_{c}$ in bar and $V_{c}$ in $\mathrm{cm}^{3} / \mathrm{mol}$.

Acentric factor $(\omega)$ : The acentric factor was introduced by Kenneth Sunborn Pitzer in 1955. It's associated with the sphericity of the molecule force field and polarity [8]. Originally defined by Equation 17:

$$
\omega=-\log \left[\lim _{\left(\frac{T}{T_{c}}\right)=0.7}\left(\frac{P_{v p}}{P_{C}}\right)\right]-1.0
$$

where $P_{\text {vap }}$ is vapor pressure, $T_{c}$ critical temperature and $P_{c}$ critical pressure.

The definition of the equation (Equation 17) arose because monoatomic gases (Air, K-r, Xe) have $\omega \sim 0$, except for noble gases $(\mathrm{He}, \mathrm{Ne})$ and some others (e.g. Rn). All other species have positive values up to 1.5 . To obtain $\omega$ values is necessary to know the constants $\mathrm{T}_{\mathrm{c}}, \mathrm{P}_{\mathrm{C}}$ and the property $\mathrm{P}_{\text {vap }}$ at reduced temperature, $\mathrm{T} / \mathrm{T}_{\mathrm{c}}=0.7$.

Pitzer rule (PITZER) and Kesler-Lee (LEE) were selected in this work to determined $\omega$. Equation 18 was presented by [25] for $\omega$ calculation:

$$
Z_{c}=0.291-0.080 \omega
$$

According to [8], Equation 18 can be used to predict the acentric factor of strongly polar substances and associative substances. However, the authors indicate that if the critical parameters were not adequately estimated for the substance there isn't guarantee of the accuracy of the desired property.

A set of equations was developed by [26] to evaluate properties of chemical compounds such as molecular mass, normal boiling temperature, critical pressure, critical temperature and acentric factor. For the latter, the following correlations were developed (Equation 19 and Equation 20). Such models depend on the reduced boiling temperature $\left(\mathrm{T}_{\mathrm{br}}=\mathrm{T}_{\mathrm{b}} / \mathrm{T}_{\mathrm{c}}\right)$ and the characterization factor of Watson $\left(\mathrm{K}_{\mathrm{w}}\right)$.

For $\mathrm{T}_{\mathrm{br}}>0,8$ :

$$
\begin{gathered}
\omega=-7.904+0.1352 \mathrm{~K}_{\mathrm{w}}-0.007465 \mathrm{~K}_{\mathrm{w}}^{2}+8.359 \mathrm{~T}_{\mathrm{br}} \\
+\frac{\left(1.408-0.01063 \mathrm{~K}_{\mathrm{w}}\right)}{\mathrm{T}_{\mathrm{br}}}
\end{gathered}
$$


For $\mathrm{T}_{\mathrm{br}}<0,8$ :

$$
\omega=\frac{-\ln P_{c}-5.92714+\frac{6.09648}{T_{b r}}+1.28862 \ln T_{b r}-0.169347 T_{b r}^{6}}{15.2518-\frac{15.687}{T_{b r}}-13.4721 \ln T_{b r}+0.43577 T_{b r}^{6}}
$$

The Watson factor can be defined by Equation 21:

$$
K_{w}=\frac{M T_{b}^{1 / 3}}{d_{15^{\circ} C}}
$$

where $\mathrm{MT}_{\mathrm{b}}$ is the average of the normal boiling temperature given in ${ }^{\circ} \mathrm{R}$ and $\mathrm{d}$ is the relative density measured at $15^{\circ} \mathrm{C}$.

Enthalpy formation and Gibbs free energy of formation in the standard state: The knowledge of standard enthalpy of formation $\left(\Delta \mathrm{H}_{\mathrm{f}}^{0}\right)$ is important to provide the enthalpy reaction for the formation of a mol of a substance from the chemical elements that constitute it, in its reference states.

The Gibbs free energy formation $\left(\mathrm{G}_{\mathrm{f}}^{0}\right)$ is defined as Gibbs' energy reaction for the formation of a mol of a substance from the chemical elements that constitute it in its reference states. According to [27], Gibbs free energy can be obtained from calorimetric data (enthalpy and entropy, from calorific capacities), equilibrium constants in chemical reactions, electrochemical measurements and spectroscopy data, when in the gas phase.

Rarely values for the calculation of the reaction Gibbs energy are found. Methods of contributions from groups such as [15], [28],[16] and others, have been of great help in predicting reliable estimates of values of formation enthalpy, absolute entropy and Gibbs free energies.

Groups contribution to $\mathrm{G}_{\mathrm{f}}(298.15 \mathrm{~K})$ and $\mathrm{H}_{\mathrm{f}}(298.15 \mathrm{~K})$ were obtained by [16] through equations (Equation 22 and Equation 23).

GANI:

$$
\begin{aligned}
& H_{f}^{0}=10.835+\sum_{k} N_{k}\left(H_{f k}\right) \\
& G_{f}^{0}=-14.828+\sum_{k} N_{k}\left(G_{f k}\right)
\end{aligned}
$$

$\mathrm{N}_{\mathrm{k}}$ represents the number of groups and $\mathrm{H}_{\mathrm{fk}}$ and $\mathrm{G}_{\mathrm{fk}}$ the group's contribution to enthalpy and Gibbs energy, respectively.

The method of [28] can also be used to estimate formation enthalpy and absolute entropy of chemical compounds in the gas phase, considering the standard state. In this method, contributions are given only to atoms with valence greater than one. Groups are linked to key atoms with specific nomenclature (Equation 24, Equation 25, and Equation 26). For example, group $\mathrm{C}-(\mathrm{C})(\mathrm{H})_{3}$ is a reference to the carbon atom (key atom) bound to another carbon and three hydrogens.

BENSON:

$$
\begin{gathered}
\Delta H_{f}^{0}(298,15 K)=\sum_{k} N_{k}\left(\Delta H_{f k}^{0}\right) \\
\Delta G_{f}^{0}(298,15 K)=\Delta H_{f}^{0}(298,15 K)-298,15 \Delta S_{f}^{0} \\
\Delta S_{f}^{0}(298,15 K)=\sum_{k} N_{k}\left(\Delta S_{f k}^{0}\right)-R \ln \sigma+\ln \eta
\end{gathered}
$$

where $\sigma$ is the symmetry of the molecule and $\eta$ the number of isomers. $\mathrm{R}$ is the universal constant of gases.

The Joback and Reid method [15] is an extension of the Lydersen method [24]. It's a method that uses additive contributions and no contribution to interactions between groups. According to the authors, it is not a high-precision method, but works well for many chemical species. Among these properties, those of interest for this work are Gibbs free energy estimates of standard formation and enthalpy of standard formation. Equation 27 and Equation 28 are used by this method to estimate these two properties.

\section{JOBACK}

$$
\begin{aligned}
& H_{f}^{0}=68.29+\sum_{k} N_{k}\left(H_{f k}\right) \\
& G_{f}^{0}=53.88+\sum_{k} N_{k}\left(G_{f k}\right)
\end{aligned}
$$

$\mathrm{N}_{\mathrm{k}}$ represents the number of groups, $\mathrm{H}_{\mathrm{fk}}$ contribution to enthalpy formation and $G_{\mathrm{fk}}$ contribution to Gibbs free energy of formation of groups $\mathrm{k}$.

The highlight the similarity of Equation 22 and Equation 27 , for the calculation of the enthalpy of formation in the GANI and JOBACK methods, respectively. The main difference in these equations lies in the identification of group k. It's known that the GANI method considers second-order interactions, consequently, the groups identified by this method may be different from that obtained by JOBACK. Similarly, it happens in Equation 23 and Equation 28 for Gibbs energy calculation.

Vapor pressure ( $\left.\mathbf{p}_{\mathrm{vap}}\right)$ : The fragment-based method [19] and the Clausius-Clapeyron equation were applied to estimate vapor pressures of TAGs using Equation 29. As it wasn't possible to find experimental data for vapor pressures of unsaturated TAGs, then was considered that the chains of saturated and unsaturated fatty acids have identical vapor pressures when they have the same number of carbon atoms for the fragment approach.

ZONG:

$$
\log P(T)=\frac{-\Delta G_{\theta}^{v a p}}{R \theta \ln 10}+\frac{\Delta H_{\theta}^{v a p}}{R \theta \ln 10}\left(\frac{1}{\theta}-\frac{1}{T}\right)
$$

where $\mathrm{P}$ is the vapor pressure $(\mathrm{Pa}), \mathrm{T}$ is the absolute temperature $(\mathrm{K}), \mathrm{R}$ is the constant of the gases, $\theta$ is the reference temperature $(\theta=298.15 \mathrm{~K}), \Delta \mathrm{H}_{\theta}$ vap is the vaporization enthalpy at the reference temperature $\theta$, and $\Delta \mathrm{G}_{\theta}$ vap is the Gibbs energy of vaporization at the reference temperature $\theta$.

A group contribution method was proposed to estimate vapor pressure and heats of vaporization as a function of the temperature of organic liquids found in the oil and biofuel industries [29]. The regression of the parameters was based on an extensive database, composed of fatty acids, esters of methyl, ethyl, propyl and butyl, tri-, di- and monoacylglycerols and hydrocarbons. This methodology improved the predictions obtained by [18] method, due to the inclusion of new experimental data of esters and acylglycerols (in addition to hydrocarbons) and critical points. Like this, the equation 30 was used to calculated of vapor pressure $\left(\mathrm{P}_{\text {vap }}\right)$. The pressure is in $\mathrm{Pa}$ and temperature in $\mathrm{K}$. 
CERIANI:

$$
\begin{gathered}
\ln \left(P^{\text {vap }}\right)=A+\frac{B}{T}+C \cdot \ln (T) \\
A=\sum_{k} N_{k}\left(A_{1 k}+M_{M} \cdot A_{2 k}\right)+\left(s_{0}+N_{C s} \cdot s_{1}\right) \\
+\alpha\left(f_{o}+N_{C} \cdot f_{1}\right) \\
B=\sum_{k} N_{k}\left(B_{1 k}+M_{M} \cdot B_{2 k}\right)+\beta\left(f_{o}+N_{C} \cdot f_{1}\right) \\
C=\sum_{k} N_{k}\left(C_{1 k}+M_{M} \cdot C_{2 k}\right)
\end{gathered}
$$

$\mathrm{N}_{\mathrm{k}}$ is the number of $\mathrm{k}$ groups in the molecule, $\mathrm{MM}$ is the molecular mass of the component, $\mathrm{N}_{\mathrm{Cs}}$ is the number of carbons of the alcoholic part of methyl and ethyl esters $\left(\mathrm{N}_{\mathrm{cs}}\right.$ equals 1 and 2, respectively), $\mathrm{NC}$ is the total number of carbon atoms in the molecule. $A_{1 k}, B_{1 k}, C_{1 k}, A_{2 k}, B_{2 k}, C_{2 k}, \alpha, \beta, s_{0}, s_{1}, f_{0}$ and $f_{1}$ are the parameters obtained by regression.

The model for predicting vapor pressure and heat of vaporization from organic compounds to the critical point using the same sets of functional groups as proposed in [18] was improved by [29], but with another dependence on temperature. The authors' proposal was a consequence of the works of [30] and [31], which indicated the limitation of the equation of determination of vaporization enthalpies at a temperature range.

Vaporization enthalpy (Hvap): A model to predict vaporization heat from the Clausius-Clapeyron equation (Equation 31) was developed by [30] and the group contribution method of [18] (Equation 32). After substitution and manipulating in the Clausius-Clapeyron equation, an equation for $\Delta \mathrm{H}_{\text {vap }}$ was obtained as a function of temperature (Equation 33).

$$
\begin{gathered}
\frac{d P_{i}^{\text {vap }}}{d T}=\frac{P_{i}^{v a p} \Delta H_{i}^{\text {vap }}}{R T^{2}} \\
P_{i}^{v a p}=\exp \left(A_{i}+\frac{B_{i}}{T^{1.5}}-C_{i} \ln T-D_{i} T\right) \\
\Delta H_{i}^{v a p}=-R\left(\frac{1.5 B_{i}}{\sqrt{T}}+C_{i} T+D_{i} T^{2}\right)
\end{gathered}
$$

$R$ represents the universal constant of gases and $B_{i}, C_{i}$ and $D_{i}$ are the parameters of the same contribution group used to estimate the vapor pressure in [18]. In high temperature and high vapor pressure conditions, the ideal gas condition made in the equation (Equation 33) isn't valid. Therefore, [30] included a correction term, which originated Equation 34.

$$
\Delta H_{i}^{v a p}=-R\left(\frac{1,5 B_{i}}{\sqrt{T}}+C_{i} T+D_{i} T^{2}\right)\left(1-\frac{T_{c}^{3} P_{i}^{v a p}}{T^{3} P_{c}}\right)^{0.5}
$$

$\mathrm{P}_{\mathrm{i}}^{\text {vap }}$ is the vapor pressure of component $\mathrm{i}$ and $\mathrm{Tc}$ and $\mathrm{Pc}$ are critical temperature and critical pressure respectively.

Changes in the previous prediction model for calculating heat of vaporization were made by [29] to obtain a wider range of compounds. Thus, the authors studied several compounds available in the databases so that the parameters of the equation for the calculation of vaporization heat were updated.
A linear equation to estimate heat of vaporization was used by [25]. $\Delta \mathrm{H}_{\mathrm{vap}}$, as a function of reduced temperature (Tr) and acentric factor $\omega$. This expression was derived in an analytical equation [31], through an approximation of the correlation of 0.6 $<\operatorname{Tr}<1.0$ (Equation 35).

$$
\frac{\Delta H_{v a p}}{R T_{c}}=7.08\left(1-T_{r}\right)^{0.354}+10.95 \omega\left(1-T_{r}\right)^{0.456}
$$

[32] applied another group contribution method to estimate vaporization heat for several substances as a function of reduced temperature (Equation 36).

$$
\Delta H_{v a p}=A\left(1-T_{r}\right)^{\alpha} \exp \left(-\alpha T_{r}\right)
$$

$\Delta \mathrm{H}_{\text {vap }}$ represents vaporization heat, $\mathrm{T}_{\mathrm{r}}$ at reduced temperature, and $\mathrm{A}$ and $\alpha$ are contributing parameters of the group.

[19] used Equation 29 to predict vaporization enthalpy. The vaporization heat appears from the correlation of vapor pressure by Antoine's equation. Temperature dependence with vaporization heat was not evaluated.

Density ( $\rho)$ : Rackett's modified equation was used to estimate the density of liquid vegetable oils [33]. First, the density of the liquid mixture of free fatty acids was estimated and then a correction factor was added to describe the shape of the TAGs (Equation 37). No correction factors were presented for DAGs and MAGs.

$$
\rho=\frac{\sum x_{i} M M_{i}}{R\left(\frac{\sum x_{i} T_{c i}}{P_{c i}}\right)\left(\sum x_{i} Z_{R A i}\right)^{\left[1+\left(1-T_{r}\right)^{\frac{2}{7}}\right]}}+F_{c}
$$

where $\mathrm{x}_{\mathrm{i}}, \mathrm{MM}_{\mathrm{i}}, \mathrm{Tc}_{\mathrm{i}}, \mathrm{Pc}_{\mathrm{i}}$, and $\mathrm{Z}_{\mathrm{RAi}}$ are molar fractions, molecular mass, critical temperature, critical pressure and Rackett parameter, respectively, of each fatty acid $i \mathrm{~T}_{\mathrm{r}}$ is the reduced temperature. The density is given in $\mathrm{kg} / \mathrm{m} 3$.

The fragment-based approach was proposed by [19] to estimate the molar volume of each fragment with dependence on temperature, and then estimated the molar volume of the liquid based on the composition and contribution of each fragment (Equation 38).

$$
v^{L}=\sum_{A} N_{f r a g, A} v_{A}^{L}(T)
$$

$v_{\mathrm{A}}{ }^{\mathrm{L}}$ is the molar volume of the liquid of each fragment and $\mathrm{N}_{\text {frag, }}$ is the number of fragments $\mathrm{A}$ in a component.

[34] extended the method of group contribution developed by [35] to predict the densities of pure liquid compounds (Equation 39).

$$
\rho=\frac{M M}{v}=\frac{M M}{\sum n_{i} \Delta v_{i}}
$$

where MM molecular mass and $v$ molar volume.

Heat capacity (cp): The fragment-based method to estimate the heat capacity of TAGs, DAGs and MAGs was described by [19]. Fragments of FAs and MAGs were expressed as linear temperature-dependent equations (Equation 40). Unsaturated fatty acid fragments were assumed to be identical. 


$$
C_{p}^{L}=\sum_{A} N_{f r a g, A} C_{p, A}^{L}(T)
$$

where $\mathrm{N}_{\text {frag,A }}$ the number of fragments $\mathrm{A}$ in the component and $\mathrm{C}_{\mathrm{p}}, \mathrm{A}^{\mathrm{L}}$ is the contribution of the calorific capacity of the fragment in component A (J/kmol. K).

Ceriani et al. [30] extended their method of contribution of groups previously used for the prediction of vapor pressure of organic liquids to develop a heat capacity model with the same set of functional groups in addition to a new linear relationship as a function of the contribution of the group (Equation 41).

$$
C_{p i}^{L}=\sum_{k} N_{k}\left(A_{k}+B_{k} T\right)
$$

$\mathrm{N}_{\mathrm{k}}$ represents the number of $\mathrm{K}$ groups in the molecule, $A_{k}$ and $B_{k}$ are obtained from regression parameters.

Heat capacities for TAGs and vegetable oils was estimated by [36], primarily by Rowlinson-Bondi equation [37][38]. Equation 42 estimated the heat capacities of pure fatty acids. They then added a correction factor, based on study of [33], to predict the density of triacylglycerols. Resulting in an expression with dependence on the molecular mass of the oil (Equation 43).

$$
\begin{aligned}
& \frac{C_{p(A G)}-C_{p(A G)}{ }^{0}}{R}=1.45+0.45\left(1-T_{r}\right)^{-1}+0.25 \omega[17.11+ \\
& \left.\left.25.2\left(1-T_{r}\right)^{1 / 3} T_{r}^{-1}+1.742\left(1-T_{r}\right)^{-1}\right]\right]
\end{aligned}
$$

$c_{p(A G)}$ is the liquid specific heat of fatty acids, $c_{p(A G)}{ }^{0}$ the specific heat of the ideal gas, $R$ the universal constant of gases, $T_{r}$ the reduced temperature and $\omega$ the acentric factor.

$$
C_{p(\text { estimado })}=C_{p(A G)}+F_{c}
$$

$F_{c}$ correction factor dependent on the molecular mass of the oil.

\section{II.2 CHARACTERIZATION OF VEGETABLE OILS}

To evaluate the methods of prediction of properties correctly, one should make the choice of consistent data, that is, the composition of the studied oil sample should be as real as possible, in order to ensure that the conclusions are effective.

For soybean, sunflower and palm oil, which were used as raw material in this work, the composition used in triacylglycerols was that obtained by [39], [40], [41], respectively. These authors determined the oil profile in TAGs by high performance liquid chromatography (HPLC).

For macauba pulp oil, as the composition in TAGs, DAGs and MAGs was not found in the literature, two characterization methodologies were proposed. The first is an approach in which oil is represented by a mixture of Mixed TAG, either by (A) high resolution gas chromatography or (B) computational methodology proposed by [42]. The second approach characterizes vegetable oil as a mixture of fatty acids.

\section{Approach 1:}

\section{(A) High Performance Gas Chromatography Analysis (GC)}

The sample of macauba pulp oil was diluted in toluene at the final concentration of $0.7 \%$. GC analysis was performed without derivatization on a thermo stabilized fused silica capillary column of TG-5 HT from Thermo brand of 15 meters x $0.25 \mathrm{~mm}$ x
0.10 micrometers. The analysis was performed with hydrogen flow from $1.5 \mathrm{~mL}$ to $50^{\circ} \mathrm{C}$ under constant pressure. The initial temperature of the column was $50^{\circ} \mathrm{C}$, with a temperature increase schedule of $15^{\circ} \mathrm{C} /$ minute to $180^{\circ} \mathrm{C}$, with ramps of $7^{\circ} \mathrm{C} /$ minute up to $230^{\circ} \mathrm{C}$ and up to $350^{\circ} \mathrm{C}$ with programming of $10^{\circ} \mathrm{C} / \mathrm{min}$, remaining at this temperature for another 25 minutes. The injector was maintained at $320^{\circ} \mathrm{C}$, in the flow division mode of $1: 50$ and 1 microliter of solution was injected. The detector was maintained at $380^{\circ} \mathrm{C}$.

Internal normalization was performed to quantify triacylglycerols. Standards of palmitic acid, linoleic, monoolein, monopalmitin, diolein, dipalmitin, tripalmitin and triolein from Sigma and $\mathrm{Nu}$ Chek brands were used for identification. They were dissolved in toluene PA.

\section{(B) Computational Analysis}

The computer program was assembled in Microsoft Excel based on equations to calculate the molar percentage of triacylglycerols according to the distribution and molar composition of fatty acids present in vegetable oil.

For the characterization of the pulp oil of the macauba to be performed, the fatty acid profile was necessary. Thus, the mass composition obtained by [43].

For the construction of the oil profile studied in TAGs, 33 triacylglycerol molecules with 99 fatty acid radicals were considered, and the number of each radical in these 33 molecules was proportional to the percentage shown in composition [43]. These FA radicals were randomly distributed among the 33 molecules of TAGs.

Thus, the thermophysical properties were estimated for each mixed TAG by applying the specific prediction method and then the mixing rule was used to estimate the oil property according to the composition of mixed triacylglycerols.

Approach 2: The second approach is based on the characterization of vegetable oil as being a mixture of fatty acids. That is, the fatty acid composition of the oil is used to determine the properties of interest. This methodology has been the most used by researchers, because there is a greater amount of experimental data on the properties of pure fatty acids.

\section{RESULTS AND DISCUSSIONS}

Three statistical parameters have been used to determine the accuracy of the performed predictions: absolute deviation (AD), relative deviation (\%RD) and absolute average relative deviation (\%AARD):

$$
\begin{gathered}
\text { Absolute deviation }(A D)=\left|\mathrm{x}_{\mathrm{exp}, \mathrm{i}}-\mathrm{x}_{\mathrm{calc}, \mathrm{i}}\right| \\
\% R D=\frac{\left|\mathrm{x}_{\mathrm{exp}, \mathrm{i}}-\mathrm{x}_{\mathrm{calc}, \mathrm{i}}\right|}{X_{\text {exp }, i}} \\
\% A A R D=\frac{\sum_{i}^{N} \frac{\left|X_{\text {exp }, i}-X_{\text {calc }, i}\right|}{X_{\text {exp }, i}}}{n}
\end{gathered}
$$

$\mathrm{X}$ is the property to be evaluated, $\mathrm{n}$ is the number of experimental data, and the subscripts "exp" and "calc" indicate the experimental and calculated property, respectively. 


\section{III.1 ESTIMATION OF THERMODYNAMIC PROPERTIES}

The estimated properties for TAGs, DAGs, MAGs and FAs, which will be discussed below, are available in the supplementary materials.

Normal boiling temperature (Tb): First, normal boiling temperatures for triacylglycerols were estimated, whose experimental data were found in the literature. The contribution methods of JOBACK and GANI groups, and the method based on ZONG fragments were evaluated and the estimated data are represented in Figure 2.

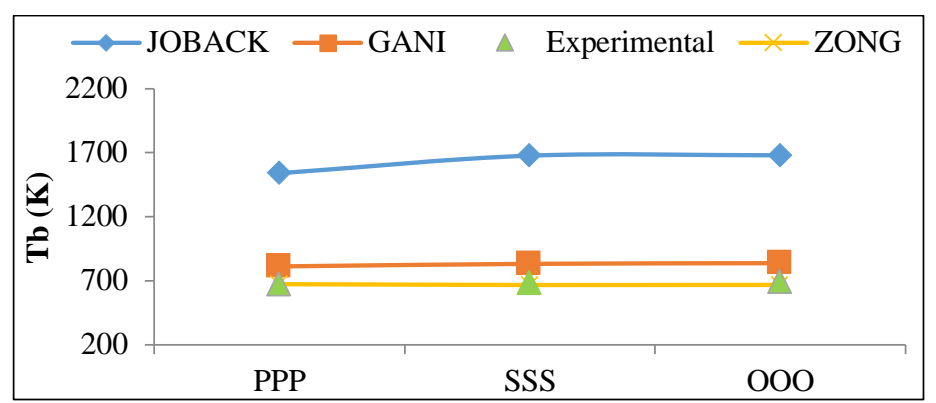

Figure 2: Estimated normal boiling temperatures (K) for PPP

(tripalmitin), SSS (tristearin) and OOO (triolein).

Source: Authors, (2020).

Figure 2 shows the $t_{b}$ estimated for three simple triacylglycerols, PPP, SSS and OOO, compared to experimental data obtained in [44], [45] [38]. The results show that the $T_{b}$ values calculated by the JOBACK method have high deviations (AARD> $100 \%$ ). The lowest absolute average relative deviation was reached when the ZONG method was used (AARD=1.9\%), followed by $21 \%$ for GANI. Thus, the ZONG method was used in this work to calculate $T_{b}$ for vegetable oils, in the TAG approach.

Since no experimental data from The MAGs and DAGs were found in the literature, the method adopted for the determination of $\mathrm{T}_{\mathrm{b}}$ was the ZONG method, which observed lower deviations for the TAGs analyzed, as shown above.

The relative deviations of the estimate of $\mathrm{T}_{\mathrm{b}}$ for fatty acids according to JOBACK and GANI are presented in Figure 3. The experimental data used are found in [21] and [46]. It's noteworthy that it wasn't possible to apply the fragment-based methodology proposed by [19] for these compounds.

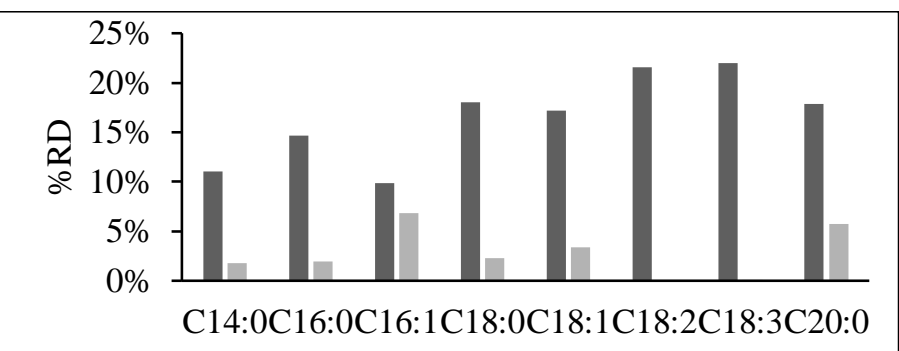

- JOBACK $\quad$ GANI

Figure 3: Relative deviations (\%) for normal boiling temperature for fatty acids in the JOBACK and GANI methods.

Source: Authors, (2020).

By the analysis of Figure 3, it is observed that the greatest deviation of the GANI method occurred in unsaturated fatty acid C16:1. The absolute average relative deviation (AARD) found for saturated fatty acids was $15.4 \%$ for the JOBACK method and $2.9 \%$ for GANI. On the other hand, unsaturated FAs gave AARD equal to $17.6 \%$ and $2.5 \%$ for the same methods, respectively. This analysis shows the agreement of the estimation of $\mathrm{T}_{\mathrm{b}}$ by the GANI method for both saturated and unsaturated AGs.

$A T_{b}$ curve as a function of the molar mass of saturated and unsaturated FAs was constructed to improve previous analysis (Figure 4). In this figure, the boiling points of saturated fatty acids (continuous line) show an almost linear characteristic. In addition, it can be noted the proximity of the experimental data with the values estimated by the GANI method.

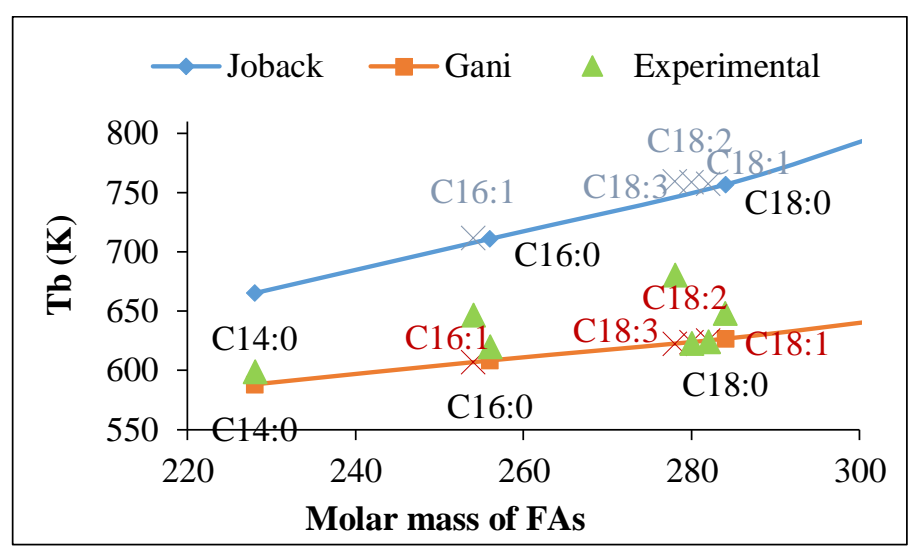

Figure 4: Normal boiling temperatures (K) estimated as a function of molar mass for fatty acids. X represents unsaturation. Source: Authors, (2020).

It's important to highlight that, in a simulation study of biodiesel production, an error in the value of $\mathrm{T}_{\mathrm{b}}$ will imply in the erroneous prediction for other properties, such as critical properties. This fact leads to erroneous results when properties, such as viscosity and density, are calculated using equations and correlations incorporated into commercial simulators.

Critical properties $\left(\mathrm{P}_{\mathrm{c}}, \mathrm{V}_{\mathrm{c}}, \mathrm{T}_{\mathrm{c}}\right.$ and $\left.\mathrm{Z}_{\mathrm{c}}\right)$ : Critical properties were estimated for TAGs, DAGs and MAGs for AMBROSE [23], JOBACK [15], GANI [16] and LYDERSEN [24] methods.

It's important to mention that only critical temperature data from some AGs were found [46]. No values were available for TAGs, DAGs and MAGs. However, they were considered enough to point out the most precise method.

The AARD obtained for the predicted critical temperatures for the AGs compared to the experimental data are $3.31 \%, 0.52 \%, 3.57 \%$ and $2.40 \%$, respectively, for the JOBACK, GANI, LYDERSEN and AMBROSE methods.

It's noted that the GANI method presented an average of the smaller relative deviations for fatty acids (AARD=0.52\%). In addition, this method is the only one among those evaluated that requires, as input, only the molecular structure (ASPEN TECH, 2014). Thus, this methodology was chosen to predict the critical properties of the components of vegetable oils.

Critical properties were estimated for several compounds involved in biodiesel production by [47]. Fatty acids, triacylglycerols and methyl esters were analyzed. The authors compared the data obtained with experimental data and pointed to GANI as the most accurate method, compared to the other two studied, [15] and [48].

The critical properties were estimated using the methods of [23] and [15] by [49]. According to the authors, in these two methods the critical temperature estimation is dependent on the normal boiling temperature. Therefore, the critical temperature was also evaluated by the authors by [50], in which the critical temperature is independent of the normal boiling temperature. According to [49], the Joback method presented the lowest 
deviations for critical volume and Ambrose's method presented the smallest deviations from the data available in [46] for critical temperature and pressure.

[51] evaluated the critical temperature by the methods of [50], [15] and [24]. Comparing the results with predicted values in [46], the authors selected the Lydersen and Joback groups and highlighted the success of these methods because they considered the experimental value of normal boiling temperature in the prediction of critical temperature.

Acentric factor ( $\omega)$ : The data estimated by [25], [26] and [26] showed similar results, as can be seen in Table 2 .

Table 2: Estimated data of the acentric factor for trilinolinin (LLL), dilinolein (LL) and monolein (L).

\begin{tabular}{|l|c|c|}
\hline Components & Pitzer & Kesler-Lee \\
\hline LLL & -0.6524 & -0.6343 \\
\hline LL & -0.3183 & -0.3183 \\
\hline L & 1.0146 & 1.0692 \\
\hline \multicolumn{2}{|c|}{ Source: Authors, (2020). }
\end{tabular}

In this work, the Pitzer rule was adopted for the determination of the acentric factors of all compounds, as it's the most used method according to [37].

Enthalpy of formation and Gibbs free energy formation in the standard state $\left(\mathbf{H}_{\mathbf{f}}^{\mathbf{0}} \mathbf{e} \mathbf{G}_{\mathbf{f}}^{\mathbf{0}}\right)$ : Initially, the formation enthalpy data were evaluated for TAG (triolein-OOO), DAG (diolein-OO) and MAG (monoolein-O) compared to data available in the literature [52], [53].

Table 3 shows the absolute deviations obtained for each method used in estimating this property. It is noted that the evaluated methods presented relative mean deviations below $3 \%$. The lowest AARD was observed when GANI (0.75\%) was used, followed by JOBACK $(0.95 \%)$. However, the GANI method requires normal boiling temperature as input. Thus, to avoid the error associated with a previously estimated measurement, the method chosen in this work was JOBACK. This requires as input only the molecular structure of the compounds. The Gibb's free energies also were calculated by JOBACK for TAGs, DAGs and MAGs.

Table 3: AD and AARD of the standard energy of formation of TAG, DAG and MAG.

\begin{tabular}{|c|c|c|c|c|}
\hline & DIPPR & \multicolumn{3}{|c|}{ Absolute deviation (kJ/mol) } \\
\cline { 3 - 5 } & $\mathbf{8 0 1}(\mathbf{k J} / \mathbf{m o l})$ & JOBACK & GANI & BENSON \\
\hline$O O O$ & -2161 & 14.415 & 1.078 & 35.053 \\
\hline$O O$ & -1670 & 14.844 & 16.090 & 44.916 \\
\hline$O$ & -1175 & 15.345 & 14.681 & 45.660 \\
\hline & $\boldsymbol{A A R D ( \% )}$ & $\mathbf{0 . 9 5 4}$ & $\mathbf{0 . 7 5 4}$ & $\mathbf{2 . 7 3 3}$ \\
\hline
\end{tabular}

Source: Authors, (2020).

For the FAs, only data from stearic acid formation enthalpy $(-884.7 \mathrm{~kJ} / \mathrm{mol})$ were obtained in the literature. The absolute deviations (AD) found for the methods of JOBACK, GANI and BENSON, respectively, were 119.58, 121.14 and $389.22 \mathrm{~kJ} / \mathrm{mol}$. Therefore, the first method was chosen to predict the formation energy for fatty acids.

For Gibbs free energy, the method chosen for fatty acids was BENSON [37]. According to [54], this is more accurate in estimating this property compared to GANI and JOBACK methods, considering the effects of neighboring atoms on calculations.

Vapor pressure (PvAP): The vapor pressure was initially evaluated for simple TAGs by the group contribution method [29] and fragment-based method [19], [55]. Figure 5 compares the estimated $\mathrm{P}_{\text {vap }}$ data compared to experimental data for tristearin (SSS) and tripalmitin (PPP), obtained in [56].

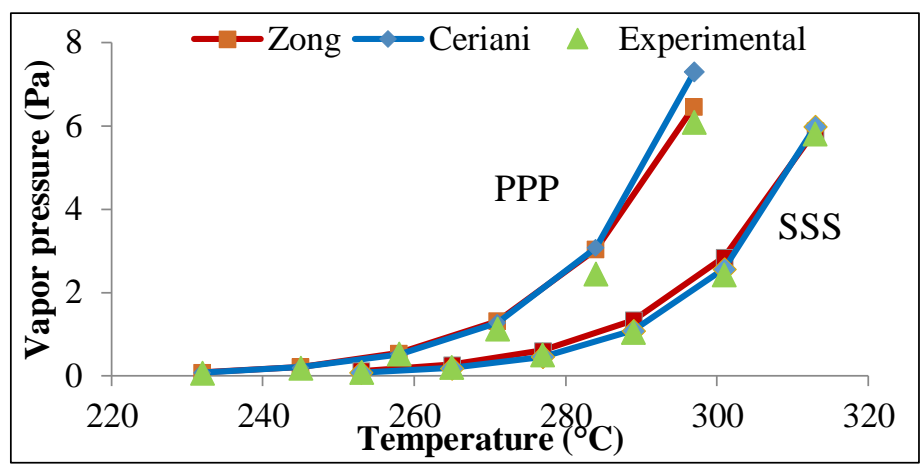

Figure 5: Experimental and estimated steam pressure (Pa) data for tripalmitin (PPP) and tristearin (SSS).

Source: Authors, (2020).

The methods of [29], [19], [55] showed similar predictions for TAGs as shown in Figure 5. The means of the deviations of the estimated steam pressures, in the temperature range of 230 to $313^{\circ} \mathrm{C}$, for the simple triacylglycerols tripalmitin (PPP) and tristearin (SSS) were respectively 15.01 and 20.04 for ZONG and 6.63 and 19.58 for CERIANI. This resulted in AARDs for the ZONG method of $17.52 \%$ and for CERIANI $13.11 \%$. By the analysis of the AARDs, the method of [29] showed higher accuracy, so it was pointed to the estimation of steam pressure for TAGs.

Moreover, according to [29], the proposed method can represent any number of fatty and hydrocarbon compounds with the lowest number of parameters and can extrapolate the temperature (critical point), by correctly describing the vapor pressures and vaporization heats.

Enthalpy of vaporization (HvaP): Table 4 shows the estimated values for enthalpy of vaporization compared to data obtained from [46].

According to the analysis in Table 4, the lowest AARD was observed for the Basarova method (AARD $=2.68 \%)$, followed by Ceriani $(\mathrm{AARD}=10.05 \%)$ and Pitzer $(\mathrm{AARD}=25.55 \%)$. It is noteworthy that, for the methods of [25] and [32], it is necessary to inform the critical temperatures and pressures, and the acentric factors of the TAGs.

Table 4: Relative deviations (RD) and absolute average relative deviation (AARD) of enthalpy of vaporization.

\begin{tabular}{|c|c|c|c|c|c|}
\hline & \multirow{2}{*}{$\begin{array}{c}\text { Temp. } \\
\left({ }^{\circ} \mathbf{C}\right)\end{array}$} & $\begin{array}{c}\text { Exp. } \\
(\mathbf{k J / m o l})\end{array}$ & {$[29]$} & {$[25]$} & $\begin{array}{c}\text { Basar } \\
\text { ova } \\
{[32]}\end{array}$ \\
\cline { 4 - 6 } & & & & & \\
SSS & $247-314$ & 164.63 & 13.84 & 27.74 & 2.89 \\
\hline PPP & $232-300$ & 158.53 & 6.27 & 23.36 & 2.47 \\
\hline & & $\boldsymbol{A A R D}(\boldsymbol{\%})$ & $\mathbf{1 0 . 0 5}$ & $\mathbf{2 5 . 5 5}$ & $\mathbf{2 . 6 8}$ \\
\hline
\end{tabular}

Source: Authors, (2020).

For [31] indicated Basarova and Svoboda method to predict enthalpy of vaporization values when the Ceriani and Meirelles method (2004) was used [31]. In turn, [29] corrected the temperature limitations of the previously proposed method [18]. So, the method adopted in this study to predict $\triangle$ hvap of TAGs, DAGs and MAGs was Ceriani [29].

Density ( $\rho)$ : Table 5 compares density predictions by [19], [33], [34], [55] to experimental data of simple TAGs [57-59]. 
Table 5: Densities estimated for simple TAGs.

\begin{tabular}{|c|c|c|c|}
\hline \multirow{2}{*}{ Components } & \multicolumn{3}{|c|}{ AARD (\%) } \\
\cline { 2 - 4 } & HALVROSEN & ZONG & IHMELS \\
\hline PPP & 0.3 & 0.2 & 1.1 \\
\hline SSS & 3.6 & 4.0 & 2.7 \\
\hline OO & 2.8 & 2.1 & 1.5 \\
\hline LLL & 1.2 & 0.1 & 1.4 \\
\hline \multicolumn{4}{|c|}{ Source: Authors, (2020). } \\
\hline
\end{tabular}

All four methods evaluated ensure accuracy by predicting density for TAGs in the temperature range from $80^{\circ} \mathrm{C}$ to $100^{\circ} \mathrm{C}$. The means of the deviations found were low, not exceeding $4.0 \%$.

The method described in [33] doesn't have adequate correction factors for the DAGs and MAGs of the Rackett equation to estimate the density of vegetable oils. In addition, the method of contribution of groups showed in [34] isn't particularly designed for predictions of lipid compound density. In other words, there isn't specific group to describe the portion of glycerol in TAGs, DAGs, MAGs and oils. Therefore, groups $\mathrm{CH} 2, \mathrm{CH}, \mathrm{CH} 2 \mathrm{OH}$, and $\mathrm{CHOH}$ should be used as substitutes when describing the portion of glycerol. To improve the accuracy of the method, data should be developed for the glycerol group.

While the methods described by [19], [55] were based on fragments, generally more accurate than group contribution methods. Also, can be to observe an increasing order to AARDtotal of densities estimated like: ZONG $(1.6 \%)<\operatorname{IHMELS}(1.7 \%)<$ HALVROSEN (2.0\%). Then, the ZONG method was chosen to predict the densities of TAGs, DAGs and MAGs

Figure 6 illustrates the good agreement of the [34] method for the calculation of the density of fatty acids. For this comparison, experimental data from [60] were used and [61]. In this, continuous lines are estimated data and points are experimental values, equal colors mean the same fatty acid.

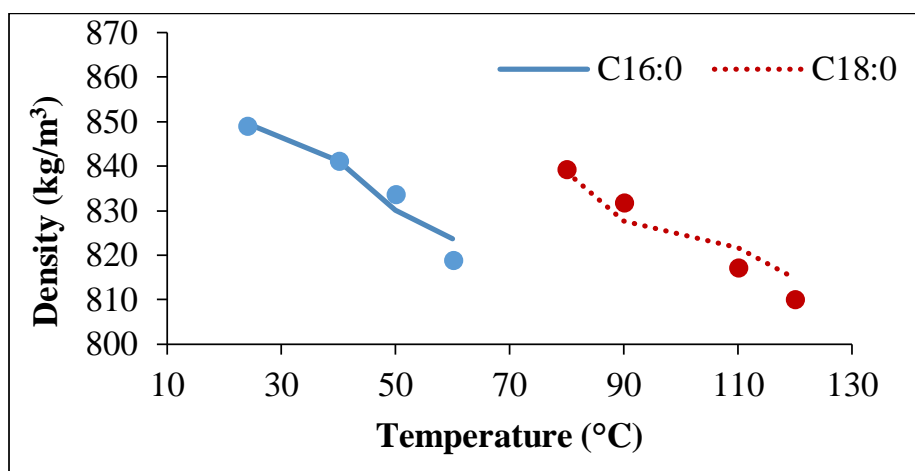

Figure 6: Densities $\left(\mathrm{kg} / \mathrm{m}^{3}\right)$ estimated as a function of the temperature of FAs. Continuous lines represent the estimated data and the points experimental values obtained from the literature.

Source: Authors, (2020).

The AARD (\%) obtained for fatty acids for the [34] method was low $(0.30 \%)$. Showing that the method is accurate when estimating the density for these compounds.

Heat capacity (cp): The deviations of estimated heat capacities compared to experimental data from [58] and [36] can be seen in Table 6 . The data were estimated in the temperature range of $60-180^{\circ} \mathrm{C}$.

The results obtained, as shown in Table 6 , showed that the method [19] have greater accuracy than [30] and [36]. In this specific case, the AARD for the ZONG method was $0.88 \%$, while for [30] and [36] were $3.26 \%$ and $1.51 \%$, respectively. It is worth mentioning that the method of [36] is applicable only to TAGs.
Table 6: Heat capacities estimated for simple TAGs.

\begin{tabular}{|c|c|c|c|}
\hline \multirow{2}{*}{ Components } & \multicolumn{3}{|c|}{ AARD (\%) } \\
\cline { 2 - 4 } & $\begin{array}{c}\text { MORAD } \\
{[36]}\end{array}$ & $\begin{array}{c}\text { ZONG } \\
{[19]}\end{array}$ & $\begin{array}{c}\text { CERIANI } \\
{[30]}\end{array}$ \\
\hline PPP & 2.74 & 1.24 & 2.21 \\
\hline SSS & 1.10 & 1.24 & 1.33 \\
\hline OOO & 0.68 & 0.15 & 6.25 \\
\hline AARD $_{\text {total }}(\%)$ & $\mathbf{1 . 5 1}$ & $\mathbf{0 . 8 8}$ & $\mathbf{3 . 2 6}$ \\
\hline
\end{tabular}

Source: Authors, (2020).

Therefore, the methodology proposed by [19] was adopted. for the calculations of this property for TAGs, DAGs and MAGs.

\section{III.2 CHARACTERIZATION OF OILS}

\section{Approach 1:}

\section{(A) High Performance Gas Chromatography Analysis (GC)} Table 7.

The results of chromatographic analysis can be seen in

As in this technique a non-polarized capillary column was used, the analysis is qualitative and simplified, because the TAGs are separated into groups having the same number of carbon atoms, not being possible the determination of unsaturation.

Table 7: Composition of macauba pulp oil obtained by GC.

\begin{tabular}{|c|c|c|c|}
\hline Sample & \multicolumn{3}{|c|}{ Macauba pulp oil } \\
\hline TAGs & Rep. 1 & Rep. 2 & $\begin{array}{c}\text { Examples of } \\
\text { possible TAGs }\end{array}$ \\
\hline C48 & 0.77924 & 0.80121 & PPP \\
\hline C50 & 9.96296 & 9.79972 & $\begin{array}{c}\text { PPS, PPO, PPL, } \\
\text { PPLn }\end{array}$ \\
\hline C52 & 42.1804 & 41.928 & SSP \\
\hline C54 & 47.077 & 47.471 & SSS, OOO, LLL \\
\hline \multicolumn{4}{|c}{ Source: Authors, (2020). }
\end{tabular}

Note: There isn't differentiation between C18:0, C18:1 e C18:2.

A more refined separation of TAGs occurs when a polarized column is used in chromatographic analysis. Thus, in a polarized column, the separation of TAGs, such as POO and PLS, which are TAGs with the same number of carbons and degree of unsaturation, but with different polarity, can be achieved. In both non-polar and polarized columns, there is no discrimination between isomeric triacylglycerols such as POO and OPO [42].

\section{(B) Computational Analysis}

Table 8 shows the proportions of triacylglycerols through the composition of fatty acids obtained from the computational program created in this work according to the methodology cited by [42].

Table 8: Characterization of macauba pulp oil in TAGs.

\begin{tabular}{|c|c|c|c|c|c|}
\hline Groupss & TAGs & $\mathbf{\%} \mathbf{m} / \mathbf{m}$ & Groupss & TAGs & $\mathbf{\%} \mathbf{m} \mathbf{m}$ \\
\hline C50:1 & POP & 8.0 & C52:4 & PLnO & 4.0 \\
\hline C50:1 & PPoS & 2.0 & C54:2 & SOO & 4.0 \\
\hline C52:2 & POO & 28.0 & C54:3 & OOO & 26.0 \\
\hline C52:3 & OPoO & 4.0 & C54:4 & OOL & 14.0 \\
\hline C52:3 & PLO & 2.0 & C54:5 & OLL & 2.0 \\
\hline C52:4 & LOPo & 6.0 & & & \\
\hline
\end{tabular}

Source: Authors, (2020). 
The identification of triacylglycerols by groups with different numbers of carbon atoms and by different combinations of saturated and unsaturated fatty acids were made by comparing the percentage data obtained from the GC with those provided by the program created on the computer. The data in Table 9 show that the proportions of each component calculated by the computer (PC) are close to the average obtained by chromatographic analysis (GC).

Table 9: Composition of macauba pulp oil in triacylglycerols by GC and using a program elaborated on the computer (PC).

\begin{tabular}{|l|c|c|}
\hline \multirow{2}{*}{ Number of Carbons } & \multicolumn{2}{|c|}{ Composition (\%) } \\
\cline { 2 - 3 } & PC & GC \\
\hline C48 & 0.00 & 0.79 \\
\hline C50 & 10.00 & 9.88 \\
\hline C52 & 44.00 & 42.05 \\
\hline C54 & 46.00 & 47.27 \\
\hline
\end{tabular}

Source: Authors, (2020).

Thus, the list of triacylglycerols presented in Table 8, obtained by the computer program, will be considered as the composition of the macauba pulp oil for this present study. Since the mixed triacylglycerol approach is closer to reality, and the results of chromatographic analysis show that the program used for the distribution of mixed TAGs meets the data obtained experimentally.

\section{III.3 SELECTION OF THE MACAUBA OIL CHARACTERIZATION METHOD}

The choice of the appropriate characterization method is important in the prediction of thermophysical properties. Some criteria to be considered in the adoption of the method are ease of use, rigorous characterization, and satisfactory predictions. Table 8 and [43] showed the composition of macauba oil in terms of TAGs and fatty acids, respectively.

Predictions of some properties were made to compare the two approaches to oil characterization. Table 10 shows predictions of density and calorific capacity of macauba pulp oil for the approach in mixed TAGs and fatty acids.

Table 10: Densities and heat capacities by the two approaches of characterization of macauba pulp oil.

\begin{tabular}{|c|l|c|c|}
\hline \multirow{3}{*}{ Density } & Method & $\begin{array}{c}\text { TAG- } \\
\text { Mixed }\end{array}$ & Fatty acids \\
\hline \multirow{5}{*}{ Heat capacity } & {$[33]$} & 0,17 & 0,16 \\
\cline { 2 - 4 } & {$[19]$} & 0,97 & ND \\
\cline { 2 - 4 } & {$[34]$} & 1,79 & 1,83 \\
\cline { 2 - 4 } & {$[36]$} & 2,17 & 2,50 \\
\cline { 2 - 4 } & {$[19]$} & 2,20 & ND \\
\cline { 2 - 4 } & {$[30]$} & 0,56 & 0,47 \\
\hline
\end{tabular}

Source: Authors, (2020).

According to the analysis of Table 10, it can be observed that the two approaches had similar estimates, with small average of relative deviations. However, it's recommended to use the characterization of oils in mixed TAGs, because it is closer to the real.

\section{III.4 PROPERTIES OF VEGETABLE OILS}

It's known that vegetable oil is a mixture of various TAGs, DAGs, MAGs and free FAs. In this work was adopted that vegetable oils were composed only of TAGs and DAGs. To determine the properties of vegetable oils, their compositions presented above, and the predicted properties of the compounds present in the mixture were used, using the ideal mixing rule (equation 47).

$$
P_{\text {mixture }}=\sum_{i=1}^{n} x_{i} P_{\text {pure }, i}
$$

The methods adopted to predict the thermophysical properties of TAGs, DAGs and MAGs, consequently of vegetable oils, are summarized in Table 11.

Table 11: Methods adopted to predict the thermophysical properties of vegetable oils.

\begin{tabular}{|c|c|}
\hline Properties & Methods \\
\hline $\mathrm{T}_{\mathrm{b}}$ & $\begin{array}{c}\text { Zong } \text { et al. }(2010 \mathrm{a} \text { and } \\
\text { 2010b) }\end{array}$ \\
\hline$T c, P c$ e $V c$ & $\begin{array}{c}\text { Constantinou and Gani } \\
(1994)\end{array}$ \\
\hline Acentric factor $(\omega)$ & Pitzer (1995) \\
\hline Enthalpy formation $\left(H_{f 0}\right)$ & Joback and Reid $(1987)$ \\
\hline Gibbs Energy $\left(G_{f 0}\right)$ & Joback and Reid $(1987)$ \\
\hline $\mathrm{P}_{\text {vap }}$ & Ceriani et al $(2013)$ \\
\hline $\mathrm{H}_{\mathrm{vap}}$ & Ceriani et al $(2013)$ \\
\hline$\rho$ & Zong et al. $\left(2010^{\mathrm{a}}\right.$ e $\left.2010^{\mathrm{b}}\right)$ \\
\hline $\mathrm{c}_{\mathrm{p}}{ }^{\mathrm{L}}$ & Zong et al. $\left(2010^{\mathrm{a}}\right.$ e $\left.2010^{\mathrm{b}}\right)$ \\
\hline
\end{tabular}

Source: Authors, (2020).

Therefore, the estimated properties for vegetable oils were compared with experimental data available in the literature. The representation of temperature-dependent thermophysical properties, such as vaporization enthalpy $\left(\mathrm{H}_{\mathrm{vap}}\right)$, heat capacity $\left(\mathrm{c}_{\mathrm{pL}}\right)$, density $(\rho)$ and vapor pressure $\left(\mathrm{P}_{\text {vap }}\right)$ is shown in Figure7(a), Figure 7(b), Figure 7(c) and Figure 7(d), respectively.

By the analysis of Figure 7 (a), it is observed that the enthalpy of vaporization of vegetable oils decreases with increasing temperature. Heat of vaporization for soybean oil was determined by [62], $\mathrm{H}_{\mathrm{vap}}=184.9 \mathrm{~kJ} / \mathrm{mol}$. The predicted value for soybean oil in this study was in the range of 216 to $174 \mathrm{~kJ} / \mathrm{mol}$, showing that there is agreement of the predicted given with the experimental. By the analysis of Figure 7 (b), it can be observed that the calorific capacities of the analyzed vegetable oils increased linearly with the increase in temperature from 20 to $80^{\circ} \mathrm{C}$. Similar behavior was observed by [63].

Density and viscosity for babassu, buriti, Brazil nut, macadamia and grape seed oils were obtained by [38]. The densities found were from 912 to $876 \mathrm{~kg} / \mathrm{m}^{3}$, in the temperature range of $20-70^{\circ} \mathrm{C}$. [64] determined the density of palm oil, $\rho=888$ $\mathrm{kg} / \mathrm{m}^{3}$ at $50^{\circ} \mathrm{C}$, close to the value found in this study $\left(880 \mathrm{~kg} / \mathrm{m}^{3}\right)$. For sunflower oil, these authors found density in the range of 880 to $945 \mathrm{~kg} / \mathrm{m}^{3}$ in the temperature range of -20 to $80^{\circ} \mathrm{C}$. Similar values were found, as shown in Figure 7 (c) [65] determined for the pulp oil of macauba densities in the range of 918.5 to 925.3 $\mathrm{kg} / \mathrm{m}^{3}$,showing again that the estimates calculated in this study reached good precision.

Vapor pressure of various vegetable oils was determined by [66]. The authors found vapor pressures for soybean oil in the range of $2.6 \mathrm{kPa}$ to $73.5 \mathrm{kPa}$, ranging from $250-330^{\circ} \mathrm{C}$. Similar values were observed, as can be seen in Figure 7 (d).

Table 12 shows the rest of the thermophysical properties that were estimated for the different vegetable oils under study, which can be able to use as input data for engineering calculations like simulations and optimize process. 


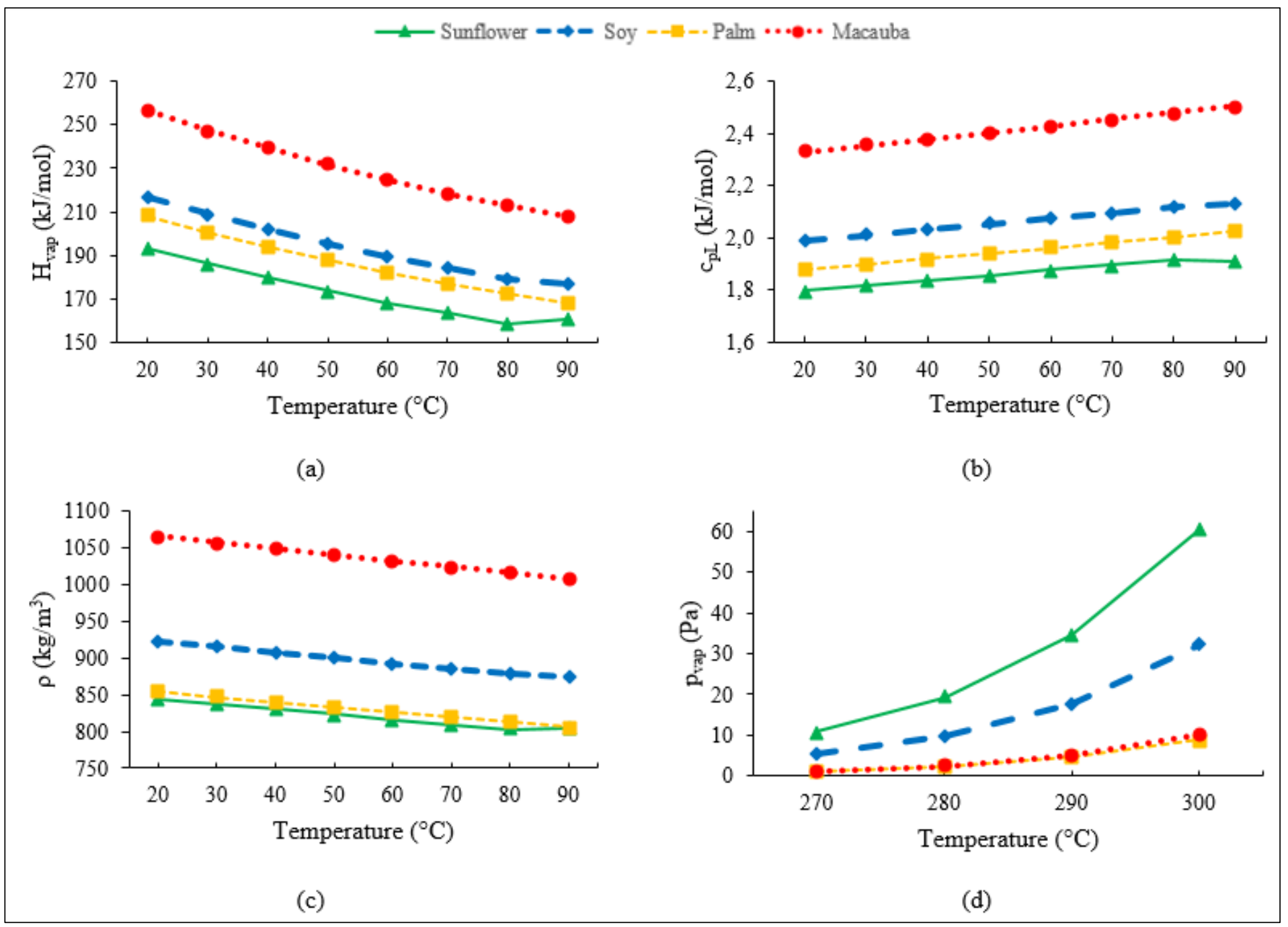

Figure 7: Estimated properties dependent on temperature (a) Vaporization enthalpy, (b) Heat capacity, (c) Density and (d) vapor pressure for sunflower $(\boldsymbol{\Delta})$, palm $(\boldsymbol{\bullet})$, soybean $(\bullet)$ and macauba pulp $(\bullet)$ oil.

Source: Authors, (2020).

Table 12: Estimated properties for vegetable oils by the methods adopted in this work.

\begin{tabular}{|l|c|c|c|c|}
\hline Properties & $\begin{array}{c}\text { Sunflowe } \\
\text { r }\end{array}$ & Soy & Palm & Macauba \\
\hline$T_{b}(\mathrm{~K})$ & 583.34 & 662.40 & 615.54 & 739.08 \\
\hline$T_{C}(\mathrm{~K})$ & 836.34 & 950.30 & 879.71 & 1051.57 \\
\hline$P_{C}\left(\mathrm{~N} / \mathrm{m}^{2}\right)$ & $2.95 \times 10^{5}$ & $3.36 \times 10^{5}$ & $3.17 \times 10^{5}$ & $3.86 \times 10^{5}$ \\
\hline$V_{C}\left(\mathrm{~m}^{3} / \mathrm{kmol}\right)$ & 2.80 & 3.18 & 2.91 & 3.48 \\
\hline$Z_{C}$ & 0.04 & 0.05 & 0.03 & 0.03 \\
\hline$H_{f}(\mathrm{~J} / \mathrm{kmol})$ & $-1.40 \times 10^{9}$ & $-1.76 \times 10^{9}$ & $-1.84 \times 10^{9}$ & $-2.09 \times 10^{9}$ \\
\hline$G_{f}(\mathrm{~J} / \mathrm{kmol})$ & $-6.95 \times 10^{7}$ & $-2.16 \times 10^{8}$ & $-3.99 \times 10^{8}$ & $-3.73 \times 10^{8}$ \\
\hline$\omega$ & -0.59 & -0.66 & -0.62 & -0.75 \\
\hline
\end{tabular}

$$
\text { Source: Authors, (2020). }
$$

Finally, the values predicted in this study are in acceptable ranges when compared with experimental data of similar vegetable oils. The difference in the composition of oils, especially in the number of unsaturation, causes changes in thermodynamic properties, as seen in the previous analyses.

\section{CONCLUSIONS}

This work showed that the modeling of properties of TAGs, DAGs, MAGs and fatty acids is closely linked to the estimation of base parameters, such as normal boiling temperature, critical temperature, pressure and volume and acentric factor. In addition, it was shown that the use of experimental data to validate the method should be carried out with caution, considering that the nature of many available data is predicted.

Prediction models of properties such as group contribution and fragment approach were evaluated to determine the normal boiling point, critical properties, vapor pressure, liquid density, calorific capacity and vaporization enthalpy of fatty acids, triglycerides, diacylglycerols and monoacylglycerols. It was possible to arrive at values similar the experimental values of the properties to vegetable oils with the application of selected methods for each property.

The estimation of the thermophysical properties of vegetable oils is of paramount importance when one wishes to evaluate biofuel production processes by simulation technique. This is because experimental data of these raw materials are scarce in the literature. Therefore, a database with values close to the actual is required for the use of simulators to have correct predictions. Thus, in this work a database was created that can be used as input parameters in simulation projects.

\section{REFERENCES}

[1] A. E. Atabani, A. S. Silitonga, I. A. Badruddin, T. M. I. Mahlia, H. H. Masjuki, and S. Mekhilef, "A comprehensive review on biodiesel as an alternative energy resource and its characteristics," 
Renewable and Sustainable Energy Reviews, vol. 16, no. 4. pp. 2070-2093, May 2012, doi: 10.1016/j.rser.2012.01.003.

[2] N. S. Evangelista, F. R. do Carmo, and H. B. de Sant'Ana, "Estimation of Vapor Pressures and Enthalpies of Vaporization of Biodiesel-Related Fatty Acid Alkyl Esters. Part 2. New Parameters for Classic Vapor Pressure Correlations," Industrial and Engineering Chemistry Research, vol. 56, no. 29, pp. 8349-8357, Jul. 2017, doi: 10.1021/acs.iecr.7b01539.

[3] N. S. Evangelista, F. R. do Carmo, and H. B. de Sant'Ana, "Estimation of Vapor Pressures and Enthalpies of Vaporization of Biodiesel-Related Fatty Acid Alkyl Esters. Part 1. Evaluation of Group Contribution and Corresponding States Methods," Industrial and Engineering Chemistry Research, vol. 56, no. 8, pp. 2298-2309, Mar. 2017, doi: 10.1021/acs.iecr.6b04772.

[4] N. S. Evangelista, F. R. do Carmo, and H. B. de Sant'Ana, "Estimation of Physical Constants of Biodiesel-Related Fatty Acid Alkyl Esters: Normal Boiling Point, Critical Temperature, Critical Pressure, and Acentric Factor," Industrial and Engineering Chemistry Research, vol. 57, no. 25, pp. 8552-8565, Jun. 2018, doi: 10.1021/acs.iecr.8b01310.

[5] M. García, J. J. Alba, A. Gonzalo, J. L. Saínchez, and J. Arauzo, "Comparison of methods for estimating critical properties of alkyl esters and its mixturesaa," Journal of Chemical and Engineering Data, vol. 57, no. 1, pp. 208-218, Jan. 2012, doi: 10.1021/je201039n.

[6] E. D. Nikitin and A. P. Popov, "Vapor-liquid critical point measurements of fifteen compounds by the pulse-heating method," Fluid Phase Equilibria, vol. 380, pp. 11-17, Oct. 2014, doi: 10.1016/J.FLUID.2014.07.038.

[7] T. Wallek, J. Rarey, J. O. Metzger, and J. Gmehling, "Estimation of pure-component properties of biodiesel-related components: Fatty acid methyl esters, fatty acids, and triglycerides," Industrial and Engineering Chemistry Research, vol. 52, no. 47, pp. 16966-16978, Nov. 2013, doi: 10.1021/ie402591g.

[8] J. P. POLING, B. E; PRAUSNITZ, J. M.; O'CONNELL, The Properties of Gases and Liquids, 5th ed. New Yord: McGraw-Hill, 2001.

[9] Y. Nannoolal, J. Rarey, and D. Ramjugernath, "Estimation of pure component properties: Part 3. Estimation of the vapor pressure of non-electrolyte organic compounds via group contributions and group interactions," Fluid Phase Equilibria, vol. 269, no. 1-2, pp. 117-133, Jul. 2008, doi: 10.1016/J.FLUID.2008.04.020.

[10] B. Moller, J. Rarey, and D. Ramjugernath, "Estimation of the vapour pressure of non-electrolyte organic compounds via group contributions and group interactions," Journal of Molecular Liquids, vol. 143, no. 1, pp. 52-63, Sep. 2008, doi: 10.1016/J.MOLLIQ.2008.04.020.

[11] T. Wallek, J. Rarey, J. O. Metzger, and J. Gmehling, "Estimation of pure-component properties of biodiesel-related components: Fatty acid methyl esters, fatty acids, and triglycerides," Industrial and Engineering Chemistry Research, vol. 52, no. 47, pp. 16966-16978, Nov. 2013, doi: $10.1021 /$ ie402591g.
[12] L. P. Cunico, A. S. Hukkerikar, R. Ceriani, B. Sarup, and R. Gani, "Molecular structure-based methods of property prediction in application to lipids: A review and refinement," Fluid Phase Equilibria, vol. 357, pp. 2-18, Nov. 2013, doi: 10.1016/j.fluid.2013.04.004.

[13] M. García, J.-J. Alba, A. Gonzalo, J. L. Sánchez, and J. Arauzo, "Comparison of Methods for Estimating Critical Properties of Alkyl Esters and Its Mixtures," Journal of Chemical \& Engineering Data, vol. 57, no. 1, pp. 208-218, 2012, doi: $10.1021 /$ je201039n.

[14] F. R. do Carmo, N. S. Evangelista, F. A. N. Fernandes, and H. B. de Sant'Ana, "Evaluation of Optimal Methods for Critical Properties and Acentric Factor of Biodiesel Compounds with Their Application on Soave-Redlich-Kwong and Peng-Robinson Equations of State," Journal of Chemical and Engineering Data, vol. 60, no. 11, pp. 3358-3381, Oct. 2015, doi: 10.1021/acs.jced.5b00638.

[15] K. G. Joback and R. C. Reid, "Estimation of Pure-Component Properties from Group-Contributions," Chemical Engineering Communications, vol. 57, no. 1-6, pp. 233-243, Jul. 1987, doi: 10.1080/00986448708960487.

[16] L. Constantinou and R. Gani, "New Group Contribution Method for Estimating Properties of Pure Compounds," AIChE Journal, vol. 40, no. 10, pp. 1697-1710, 1994.

[17] A. Fredenslund, R. L. Jones, and J. M. Prausnitz, "Groupcontribution estimation of activity coefficients in nonideal liquid mixtures," AIChE Journal, vol. 21, no. 6, pp. 1086-1099, 1975, doi: 10.1002/aic.690210607.

[18] R. Ceriani and A. J. A. Meirelles, "Predicting vapor-liquid equilibria of fatty systems," Fluid Phase Equilibria, vol. 215, no. 2, pp. 227-236, Feb. 2004, doi: 10.1016/j.fluid.2003.08.011.

[19] L. Zong, S. Ramanathan, and C. C. Chen, "Fragment-based approach for estimating thermophysical properties of fats and vegetable oils for modeling biodiesel production processes," Industrial and Engineering Chemistry Research, vol. 49, no. 2, pp. 876-886, Jan. 2010, doi: 10.1021/ie900513k.

[20] R. M. Matricarde Falleiro, L. Y. Akisawa Silva, A. J. A. Meirelles, and M. A. Krähenbühl, "Vapor pressure data for fatty acids obtained using an adaptation of the DSC technique," Thermochimica Acta, vol. 547, pp. 6-12, Nov. 2012, doi: 10.1016/J.TCA.2012.07.034.

[21] "DDB. DORTMUND DATA BANK." Available http://www.ddbst.com/ddb.html. Access: February 2019.

[22] E. D. Nikitin, P. A. Pavlov, and P. V. Skripov, "Measurement of the critical properties of thermally unstable substances and mixtures by the pulse-heating method," The Journal of Chemical Thermodynamics, vol. 25 , no. 7, pp. 869-880, Jul. 1993, doi: 10.1006/JCHT.1993.1084.

[23] D. Ambrose, "Correlation and Estimation of Vapour-Liquid Critical Properties. I Critical Temperatures of Organic Compounds," NPL Rep. Chem, no. 92, 1980. 
[24] A. L. Lydersen, "Estimation of critical properties of organic compounds," 1955.

[25] K. S. Pitzer, "The Volumetric and Thermodynamic Properties of Fluids. I. Theoretical Basis and Virial Coefficients 1," Journal of the American Chemical Society, vol. 77, no. 13, pp. 3427-3433, Jul. 1955, doi: 10.1021/ja01618a001.

[26] M. G. KESLER and B. I. LEE, "Improve Predictions of Enthalpy of Fractions.," Hydrocarbon Processing, no. 55, pp. 153$158,1976$.

[27] P. W. ATKINS, J. PAULA, and J. Keeler, Physico-chemical, Eleventh Edition. Oxford University Press, 2017.

[28] S. W. BENSON et al., "Additivity rules for the estimation of thermochemical properties," Chemical Reviews, vol. 69, no. 3, pp. 279-324, 1969.

[29] R. Ceriani, R. Gani, and Y. A. Liu, "Prediction of vapor pressure and heats of vaporization of edible oil/fat compounds by group contribution," Fluid Phase Equilibria, vol. 337, pp. 53-59, 2013, doi: 10.1016/j.fluid.2012.09.039.

[30] R. Ceriani, R. Gani, and A. J. A. Meirelles, "Prediction of heat capacities and heats of vaporization of organic liquids by group contribution methods," Fluid Phase Equilibria, vol. 283, no. 1-2, pp. 49-55, Sep. 2009, doi: 10.1016/j.fluid.2009.05.016.

[31] Y. C. Su, Y. A. Liu, C. A. Diaz Tovar, and R. Gani, "Selection of prediction methods for thermophysical properties for process modeling and product design of biodiesel manufacturing," Industrial and Engineering Chemistry Research, vol. 50, no. 11, pp. 6809-6836, Jun. 2011, doi: 10.1021/ie102441u.

[32] P. Basařová and V. Svoboda, "Prediction of the enthalpy of vaporization by the group contribution method," Fluid Phase Equilibria, vol. 105, no. 1, pp. 27-47, Mar. 1995, doi: 10.1016/0378-3812(94)02599-V.

[33] J. D. Halvorsen, W. C. Mammel, and L. D. Clements, "Density estimation for fatty acids and vegetable oils based on their fatty acid composition," Journal of the American Oil Chemists' Society, vol. 70, no. 9, pp. 875-880, 1993, doi: 10.1007/BF02545346.

[34] E. C. Ihmels and J. Gmehling, "Extension and revision of the group contribution method GCVOL for the prediction of pure compound liquid densities," Industrial and Engineering Chemistry Research, vol. 42, no. 2, pp. 408-412, 2003, doi: 10.1021/ie020492j.

[35] H. S. Elbro, A. Fredenslund, and P. Rasmussen, "Group contribution method for the prediction of liquid densities as a function of temperature for solvents, oligomers, and polymers," Industrial \& Engineering Chemistry Research, vol. 30, no. 12, pp. 2576-2582, Dec. 1991, doi: 10.1021/ie00060a011.

[36] N. A. MORAD, A. A. M. KAMAL, F. PANAU, and T. W. YEW, "Liquid specific heat capacity estimation for fatty acids, triacylglycerols, and vegetable oils based on their fatty acid composition," Journal of the American Oil Chemists' Society, vol. 77, no. 9, pp. 1001-1005, 2000, doi: 10.1007/s11746-000-0158-6.
[37] R. C. REID, J. M. PRAUSNITZ, and B. E. POLING, The properties of gases and liquids., 4th ed. New York: McGraw-Hill, 1987.

[38] R. Ceriani, F. R. Paiva, C. B. Gonçalves, E. A. C. Batista, and A. J. A. Meirelles, "Densities and viscosities of vegetable oils of nutritional value," Journal of Chemical and Engineering Data, vol. 53, no. 8, pp. 1846-1853, Aug. 2008, doi: 10.1021/je800177e.

[39] S. C. Cunha and M. B. P. P. Oliveira, "Discrimination of vegetable oils by triacylglycerols evaluation of profile using HPLC/ELSD," Food Chemistry, vol. 95, no. 3, pp. 518-524, Apr. 2006, doi: 10.1016/j.foodchem.2005.03.029.

[40] F. Ma and M. A. Hanna, "Biodiesel production: a review 1." Bioresource Technology; 70, - 1-15, 1999, https://doi.org/10.1016/S0960-8524(99)00025-5.

[41] M. N. DUNKLE, F. DAVID, and P. SANDRA, Analysis of triglycerides in vegetable oils using the Agilent 1260 Infinity Analutical SFC System with evaporative light scattering detection, 5991st-0987EN ed. Agilent Technologies Publication, 2012.

[42] N. R. Antoniosi Filho, O. L. Mendes, and F. M. Lan, "Computer Prediction of Triacylglycerol Composition of Vegetable Oils by HRGC." Chromatographia, 40, 557-562, 1995.

[43] J. C. del Río, A. B. Evaristo, G. Marques, P. Martín-Ramos, J. Martín-Gil, and A. Gutiérrez, "Chemical composition and thermal behavior of the pulp and kernel oils from macauba palm (Acrocomia aculeata) fruit," Industrial Crops and Products, vol. 84, pp. 294-304, Jun. 2016, doi: 10.1016/J.INDCROP.2016.02.018.

[44] J. W. Goodrum and D. P. Geller, "Rapid thermogravimetric measurements of boiling points and vapor pressure of saturated medium-and long-chain triglycerides." Bioresource Technology, 84, 75-80, 2002.

[45] C. M. García Santander, S. M. Gómez Rueda, N. de Lima Da Silva, C. L. de Camargo, T. G. Kieckbusch, and M. R. Wolf MacIel, "Measurements of normal boiling points of fatty acid ethyl esters and triacylglycerols by thermogravimetric analysis," Fuel, vol. 92, no. 1, pp. 158-161, Feb. 2012, doi: 10.1016/j.fuel.2011.08.011.

[46] "NIST. National Institute of Standards and Technology." Available https://www.nist.gov/. Access: February 2019.

[47] M. Sales-Cruz, G. Aca-Aca, O. Sánchez-Daza, and T. LópezArenas, "Predicting critical properties, density and viscosity of fatty acids, triacylglycerols and methyl esters by group contribution methods," 20th European Symposium on Computer Aided Process Engineering, 2010.

[48] J. Marrero and R. Gani, "Group-contribution based estimation of pure component properties," Fluid Phase Equilibria, 183-184, 2001, pp. 183-208.

[49] H. An, W. M. Yang, A. Maghbouli, S. K. Chou, and K. J. Chua, "Detailed physical properties prediction of pure methyl esters for biodiesel combustion modeling," Applied Energy, vol. 102, pp. 647-656, Feb. 2013, doi: 10.1016/J.APENERGY.2012.08.009. 
[50] R. F. Fedors, "Relationship between Chemical Structure and the Critical Temperature," Chem. Eng. Comm., 1982.

[51] K. Anand, R. P. Sharma, and P. S. Mehta, "A comprehensive approach for estimating thermo-physical properties of biodiesel fuels," Applied Thermal Engineering, vol. 31, no. 2-3, pp. 235242, Feb. 2011, doi: 10.1016/j.applthermaleng.2010.09.003.

[52] "DIPPR. National Institute of Standards and Technology." Available: https://www.nist.gov/. Access: February 2019.

[53] A. Vatani, M. Mehrpooya, and F. Gharagheizi, "Prediction of Standard Enthalpy of Formation by a QSPR Model," Int. J. Mol. Sci, vol. 8, pp. 407-432, 2007, [Online]. Available: www.mdpi.org/ijms/.

[54] "ASPEN TECH." Available:
http://www.aspentech.com/products/aspen-plus.aspx. Access: March 2020.

[55] L. Zong, S. Ramanathan, and C. C. Chen, "Predicting thermophysical properties of mono- and diglycerides with the chemical constituent fragment approach," Industrial and Engineering Chemistry Research, vol. 49, no. 11, pp. 5479-5484, Jun. 2010, doi: 10.1021/ie901948v.

[56] E. S. PERRY, W. H. WEBER, and B. F. DAUBERT, "Vapor Pressures of Phlegmatic Liquids. I. Simple and Mixed Triglycerides," J. Am. Chem. Soc., vol. 71, no. 11, pp. 3720-3726, 1949.

[57] M. A. Eiteman and J. W. Goodrum, "Density and Viscosity of Low. Molecular Weight Triglycerides and Their Mixtures," Journal of the American Oil Chemists' Society, 71 (11), pp: 1261, 1994.

[58] J. C. PHILLIPS and G. J. MATTAMAL, "Effect of Number of Carboxyl Groups on Liquid Density of Esters of Alkylcarboxylic Acids.," Journal Chemical Engineering, vol. 23, pp. 1-6, 1978.

[59] A. K. Sum, M. J. Biddy, J. J. de Pablo, and M. J. Tupy, "Predictive Molecular Model for the Thermodynamic and Transport Properties of Triacylglycerols," Journal of Physical Chemistry B, vol. 107, no. 51, pp. 14443-14451, Dec. 2003, doi: $10.1021 /$ jp035906g.

[60] H. Noureddini, B. C. Teoh, and D. Clements, "Densities of Vegetable Oils and Fatty Acids." [Online]. Available: http://digitalcommons.unl.edu/chemeng_biomaterialshttp://digital commons.unl.edu/chemeng_biomaterials/ 14 .

[61] M. J. Pratas, S. Freitas, M. B. Oliveira, S. C. Monteiro, A. S. Lima, and J. A. P. Coutinho, "Densities and viscosities of fatty acid methyl and ethyl esters," Journal of Chemical and Engineering Data, vol. 55, no. 9, pp. 3983-3990, Sep. 2010, doi: $10.1021 / \mathrm{je} 100042 \mathrm{c}$.

[62] E. G. HAMMOND, L. A. JOHNSON, C. SU, T. WANG, and P. J. WHITE, Soybean Oil. In: Bailey's Industrial Oil and Fat Products, Sixth Edition. John Wiley \& Sons, 2005.

[63] O. O. Fasina and Z. Colley, "Viscosity and specific heat of vegetable oils as a function of temperature: $35^{\circ} \mathrm{C}$ to $180^{\circ} \mathrm{C}$,"
International Journal of Food Properties, vol. 11, no. 4, pp. 738 746, Oct. 2008, doi: 10.1080/10942910701586273.

[64] L. R. STRECKER, M. A. BIEBER, A. MAZA, T. GROSSBERGER, and W. J. DOSKOCZYNSKI, Bailey's Industrial Oil and Fat Products, Fifth Edition. New York: Wiley, 1996.

[65] H. S. RODRIGUES, “Obtenção de ésteres etílicos e metílicos, por reações de transesterificação, a partir do óleo da palmeira Latino Americana macaúba - Acrocomia aculeata.," 2007.

[66] K. Murata, Y. Liu, M. Inaba, and I. Takahara, "Production of Synthetic Diesel by Hydrotreatment of Jatropha Oils Using Pt-Re/H-ZSM-5 Catalyst," Energy \& Fuels, vol. 24, no. 4, pp. 2404-2409, Apr. 2010, doi: 10.1021/ef901607t. 